Reseñas de libros e informes / Book and Report Review 


\title{
Culture and Cognition. Patterns in the Social Construction of Reality. Brekhus, Wayne H. Cambridge: Polity Press, 2015
}

\author{
Dafne Muntanyola Saura \\ Universidad Autónoma de Barcelona \\ dafne.muntanyola@uab.cat
}

Este libro publicado por Polity Press ofrece un panorama de la producción eminentemente estadounidense en cultura y cognición. Su autor, Wayne Brekhus, es profesor de sociología de la Universidad de Missouri y pertenece a la que él mismo denomina escuela zerubaveliana, en homenaje a Eviatar Zerubavel, profesor de Rutgers University. Zerubavel es el fundador de la rama culturalista de la sociología cognitiva, y sus libros Social Mindscapes (1997) y The Elephant in the Room (2006) son ya clásicos. Las referencias de Zerubavel, juntamente con las de Karen Cerulo, profesora de la misma universidad y editora de la Sociological Forum, y las de 0mar Lizardo, catedrático de la Universidad de Nôtre-Dame constituyen los tres pilares de la bibliografía de este volumen.

La razón por la cual empiezo con esta tríada es porque son nombres que delimitan el alcance de este libro. Al revisar la lista de referencias vemos cómo la panorámica de estudios sobre los elementos cognitivos de las prácticas culturales se centra en la tradición de la Costa Este. Se excluye por completo la sociología cognitiva fundacional de Aaron Cicourel (con Cognitive Sociology de 1974) y las propuestas internacionales de Marion Fourcade (2012), TiaDeNora (2014) y Bernard Lahire (2008) desde UC Berkeley, Exeter y Lyon. Los capítulos uno a cinco son un compendio de estudios empíricos sobre diversos fenómenos culturales relacionados con la percepción, la categorización, las metáforas, las identidades, el tiempo y la memoria que ofrece una visión muy parcial de la sociología cognitiva en cultura. Otra sorpresa se produce al leer la introducción y las conclusiones, los únicos capítulos teóricos del libro. Brekhus hace allí su propuesta, con una clasificación paradigmática de las producciones que él considera como propias de la sociología cognitiva de corte culturalista.

En la introducción, Brekhus resume en 5 líneas la aportación clásica de Berger y Luckmann: "La construcción social de la realidad es una idea que fue definida por primera vez y popularizada por Berger y Luckmann (1966) y es un supuesto básico para los sociólogos, aunque a menudo se da por supuesto como talón de fondo sin ser explícitamente delimitada" (p. 1). Berger y Luckmann, sin embargo, dedican más de 30 páginas de La construcción a comentar pasajes de Alfred Schütz, fenomenólogo social de la New School que brilla por su ausencia en el volumen que nos ocupa. Dejan muy claro su continuidad con la obra de Schütz, literalmente afirmando que "Personalmente debemos la percepción fundamental de la necesidad de esta redefinición a Alfred Schütz (...) Schütz se preocupó sobre todo por analizar la estructura del mundo del sentido común de la vida cotidiana" (1988: 31-32) Y un poco más abajo le citan directamente: "El conocimiento está socialmente distribuido, y el mecanismo de esta distribución podría ser el objeto de estudio de una disciplina sociológica". Parece claro que Brekhus silenciando esta tradición teórica tiene la intención de separarse de la fenomenología social en sociología y reivindicar una perspectiva teórica propia.

La matriz de autores clásicos que Brekhus presenta se resume en la frase siguiente, que constituye también un subtítulo de la introducción: "Cada una de estas orientaciones heurísticas — la cultural, la social, y la individual — tendrían como sociólogos fundadores a Émile Durkheim, Erving 
Goffman y Pierre Bourdieu respectivamente. (p. 7). Dejando de lado el adjetivo heurístico, que es más que discutible al hablar de Durkheim, un autor positivista y estructuralista, lo que llama más la atención es la distinción entre un Goffman "social", y un Bourdieu "individual". La perspectiva de Bourdieu (1984: 47), en sus propias palabras, es relacional y se opone al racionalismo estrecho y al atomismo: "En primer lugar, para romper con la tendencia a pensar el mundo social de forma sustancialista. La noción de espacio contiene, por sí misma, el principio de una aprehensión relacional del mundo social: afirma en efecto que toda la «realidad» que designa reside en la exterioridad mutua de los elementos que la componen. Los seres aparentes, directamente visibles, trátese de individuos o de grupos, existen y subsisten en y por la diferencia, es decir en tanto que ocupan posiciones relativas en un espacio de relaciones que, aunque invisible y siempre difícil de manifestar empíricamente, es la realidad más real el principio real de los comportamientos de los individuos y de los grupos". Brekhus justifica esta lectura individualista con las aportaciones de Lizardo (2004), que define el concepto de habitus como psicológico. El autor atribuye a Bourdieu la idea de que la cultura es inconsistente, fragmentada en sus usos y vinculada con el habitus de naturaleza subconsciente.

Unas páginas más abajo, Brekhus vuelve a citar a Lizardo (2008) que asocia el habitus con las neuronas espejo. Mi sorpresa es mayúscula cuando leo la frase siguiente: "Lizardo argumenta que las instrucciones directas y la socialización no son necesarias porque las prácticas pueden ser transmitidas y recogidas inconscientemente espejándose en los otros (p. 18). El autor resume en la misma página la aportación de Bourdieu al campo de lo que él considera investigación interdisciplinar entre neurociencia, ciencia cognitiva y sociología cultural: "Estos académicos enfatizan los hábitos corpóreos en las respuestas en gran medida subconscientes al entorno, en lugar de la socialización y el lenguaje como la forma primaria en la que la cultura se internaliza". Me parece indignante y muy preocupante que Polity Press publique un libro que asume tales barbaridades, ignorando conceptos de primero de carrera como el proceso de interioriza- ción que define la socialización precisamente como producto de la toma de posición del Otro Generalizado. Caer en el reduccionismo de considerar este proceso de interacción sólo como un proceso neuronal, y además, afirmar (siguiendo a Lizardo) que se trata de un proceso que no eslingüístico ni simbólico que se opone al de socialización, me parece un doble error. El problema no es buscar un habitus con una posible traducción a nivel físico neuronal. Se trata de una vinculación altamente incierta, ya que el mismo Rizzolatti (2015), descubridor junto con Gallese de las neuronas espejo, no se cansa de repetir que estas neuronas pertenecen a bonobos y que no son necesariamente equivalentes al proceso psicológico de la empatía. Pero efectivamente podemos hablar de la existencia de mecanismos biológicos, como el de la intencionalidad (Searle, 2004), la reflexividad de segundo orden (Premack, 2004) y la proyección conceptual (Kirsh, 2010), que podrían ser condiciones de posibilidad del habitus. Cito referencias de filósofos y psicólogos evolutivos que abordan de manera interdisciplinar esta misma temática desde una postura integrada y fundamentada histórica y empíricamente. Existen más omisiones: Loïc Wacquant (2004) y su propuesta de habitus corpóreo tampoco aparece en estas páginas, aun siendo discípulo directo de Bourdieu y ser el primero en vincular el término de corpóreo (embodied) con el de habitus. Desde un punto de vista de rigor académico, tampoco es aceptable que no aparezca ninguna cita directa de Durkheim, sino que sólo aparezca mediado por Rawls, de la misma forma que Razones Prácticas es la única obra citada de Bourdieu, mientras que el resto son citas indirectas de los autores que ya he nombrado aquí.

De hecho, y ya acabo esta crítica furibunda a la propuesta teórica de este volumen, tal majadería tiene consecuencias metodológicas que se desarroIlan en las conclusiones. El autor cita a Levi Martin (2011) "el poder causal de la acción individual está en la cabeza de los individuos (lo que saben, lo que quieren, lo que escogen, y cómo actúan) (p. 173). Se trata, en definitiva, de volver a la caja negra de las decisiones, basada en preferencias y creencias. Es un modelo cognitivo anticuado, propio de los primeros desarrollos cibernéticos GOFAl (Good Old Fashion Artificial Intelligence). Desde la ciencia 
cognitiva contemporánea, la cognición y las acciones están distribuidas (Hutchins, 2012), extendidas (Clark, 2001) y son corpóreas (Gibbs, 2006). No nos debería sorprender entonces la conclusión metodológica a la que llega el autor, citando a Vaisey (2009): que las entrevistas no son útiles porque no permiten llegar a la cultura del nivel subconsciente, y que por lo tanto las encuestas son herramientas mucho más adecuadas porque "la forma de responder de los encuestados es más cercana a la cognición automática, visceral (?) que utilizamos en los procesos de decisión de la cotidianidad (p. 175). Existen tantas aportaciones, no ya desde la sociología, sino desde la ciencia cognitiva y la misma psicología que contradice esta afirmación, que no sé por dónde empezar. Sólo voy a recordar que Kahneman \& Tversky (1973), premios Nobel de economía, descubrieron que los procesos de decisión heurísticos de la vida real no se corresponden con los procesos de razonamiento que tienen lugar en los experimentos y encuestas.

Los otros cinco capítulos del presente volumen son un compendio de estudios de caso, etnografías, análisis conversacionales, análisis del discurso, análisis de redes sociales y también encuestas, que por suerte se vinculan de lejos con el contenido teórico de los capítulos que hemos desmontado. El primero se titula "Percepción, atención y framing: la sociología de la relevancia y de la irrelevancia" y es el capítulo más tradicionalmente zerubaveliano, porque recoge una multitud de estudios sobre cómo filtramos culturalmente las percepciones de la realidad. También incluye estudios tan conocidos como el de Goodwin (2004) sobre la manipulación por parte de los expertos del cuerpo policial de las cintas de vídeo de maltrato al joven afroamericano Rodney King, juicio que condujo a las protestas de Los Ángeles por una sentencia exculpatoria claramente racista. Se trata de un muy buen ejemplo de "visión profesional", en la que el antropólogo y lingüista Goodwin, a través del análisis conversacional de los testimonios del juicio, muestra cómo el jurado siguió las interpretaciones de las imágenes de lo sucedido a través de las justificaciones y las objetivaciones técnicas del experto de la policía. Repito, es un muy buen estudio sobradamente conocido: Goodwin ha producido mucho más y en temas muy diversos, como relaciones intergeneracionales, de juego o musicales, siempre con el mismo rigor metodológico que huye de tergiversaciones teóricas como las que hemos visto en este volumen.

El segundo capítulo, "Clasificaciones, categorizaciones y boundary work" se centra en el proceso de dar significado simbólico a lo que vemos. № veo muy clara la diferencia entre la percepción del primer capítulo y la categorización tal como se presenta aquí. De hecho, se presentan estudios sobre clasificación racial en EUA (Saperstein y Penner, 2012) y Brazil (Brubaker et al., 2004) que se basan en cómo los ciudadanos se ven unos a otros, según su fenotipo y los estereotipos asociados. El mismo Brubaker afirma que la raza y la etnicidad son fundamentalmente formas de ver (p. 69) y yo añadiría, no sólo de ver, sino de actuar, de hablar y de categorizar. ¿En qué momento acaba la percepción y empieza la categorización? ¿Y sobre todo, por qué se trata de cognición y no simplemente de elementos simbólicos o significados compartidos? Los términos abarcan tanto que es difícil ver cuál es su referente propiamente cognitivo. Esta excesiva metaforización acompaña un estudio por otro lado muy interesante, de Karen Danna Lynch (2009) sobre las formas de rutinización y de gestión del espacio físico de los trabajadores asalariados y autónomos, que trabajan fuera y dentro de su hogar. El boundary work de estos trabajadores constituye un buen ejemplo de microestrategias significativas en la vida cotidiana.

El tercer capítulo, sobre "Meaning-making, metáforas y marcos de significado" en teoría realiza un paso más y recoge lo más "global" del proceso de percepción y clasificación. De nuevo, no se explicita un criterio para separar estos tres momentos: parece más bien que los estudios presentados adoptan distintos ángulos sobre procesos cognitivos centrados en la atención, la proyección y el lenguaje. La ambigüedad teórica de la clasificación se ve reflejada en el mismo texto, ya que Brekhus pasa a utilizar un registro excesivamente descriptivo e incluso superficial para hablar de la complejidad de la práctica social y cognitiva. "Tenemos marcos culturales de significado que modifican los significados que asignamos a los objetos y a las prácticas. Estos significados van ligados a cómo clasificamos y categorizamos cosas, 
y existe a menudo un componente moral en los significados (p. 88). Suena mal en castellano, y también en inglés: ¿a qué viene el componente moral? ¿Y qué diferencia hay entre clasificar y categorizar? El autor no ha podido obviar a George Lakoff, lingüista y científico cognitivo de UC Berkeley con una producción impresionante y con una fuerte influencia en la opinión pública americana demócrata. № obstante, su propuesta sobre la naturaleza corpórea de las metáforas se silencia, y también pasa de puntillas por sus colegas Fauconnier y Turner (2002), introductores de los términos estereotipo, metonímia y blend en el análisis lingüístico del discurso. Parece como si el uso del término "lenguaje" estuviera prohibido en este libro, cuando están presentando estudios puramente lingüísticos. Se trata de demostrar (falsamente) que la propuesta de la sociología cognitiva culturalista es una alternativa total, que no tiene nada que ver, con la fenomenología de Schütz y de Berger y Luckmann. Nada más lejos. Los estudios son los más interesantes de este capítulo de Allison Pugh (2009) y Yuki Kato (2011). La excelente etnografía de Pugh muestra cómo las prácticas de consumo de familias con dinero pasa por una "privación simbólica" que rehúye el consumismo de la marca y la acumulación de juguetes, mientras que las familias con menos recursos adoptan un estilo de consumo inverso, que la autora llama "indulgencia simbólica", en la que ceder al capricho del juguete caro que sale por la televisión pasa a ser un elemento de dignidad y de pertinencia, de integración en una sociedad capitalista. Kato analiza el discurso de los adolescentes de los suburbios californianos que llaman a su barrio "burbuja" (bubble) con connotaciones ambiguas, positivas por ser su territorio, pero también negativas por poner de relieve el aislacionismo de estas comunidades privilegiadas con un tejido social homogéneo.

El cuarto capítulo "Construcción de Identidades" agrupa los estudios que se centran en la construcción de identidades de género, étnicas, raciales, de orientación sexual y de consumo cultural. El estudio de Bethany Bryson (1996) recoge mediante una encuesta los (dis)gustos musicales de los jóvenes. Curiosamente, Brekhus pone de relieve que se trata de jóvenes omnívoros (aludiendo a Peterson) y omite mencionar que la idea de con- siderar el disgusto como elemento de distinción y de clasificación social es un concepto relacional de Bourdieu. También son de interés los estudios de McLeod (1999) y Force (2009) que exploran la idea de autenticidad y las disputas y negociaciones que se generan dentro de las subculturas juveniles del hip-hop y del punk respectivamente. $Y$ de nuevo, Danna Lynch (2011) presenta un análisis relacional a partir de entrevistas en profundidad de los múltiples roles que adoptan los padres y madres para cuidar de sus hijos y seguir con su vida cotidiana. Lynch reivindica que la alternación de roles no tiene por qué ser problemática, sino que puede ser un elemento funcional y normal del juego de roles familiares, profesionales y personales.

Finalmente, el capítulo quinto, "Memoria y tiempo" vuelve a la tradición zerubaveliana y recoge lo mejor de los estudios sobre el uso social del tiempo. Scarce (2002) describe la forma en la que los camioneros alteran sus rutinas para adaptarse a las largas horas de conducción sin dormir, convirtiéndose en "expertos del ritmo". Snyder (2012) explora las estrategias de los reclusos para construir unos horarios y un sentido del tiempo distinto al de fuera, transformando los días en horas y las semanas en días (en inglés to do time, hacer tiempo, quiere decir pasar tiempo en prisión).

En definitiva, es una vergüenza que se publiquen libros con tanta poca seriedad teórica. No obstante, saltándose la introducción y las conclusiones, en los capítulos empíricos los estudiantes de grado, de master, doctorado, y de hecho todo sociólog@ que tenga interés en la perspectiva construccionista del conocimiento de la vida cotidiana puede encontrar una lista importante de referencias sobre áreas muy heterogéneas, desde la religión hasta el género, pasando por el consumo, la cultura, las identidades y el conocimiento. Más que un libro, nos encontramos con una bibliografía comentada sobre algunos estudios norteamericanos en sociología de la cultura con perspectiva construccionista.

\section{REFERENCIAS AÑADIDAS}

Berger, P. y Luckmann, T. (1988). La construcció social de la realitat. Barcelona: Herder. 
Bourdieu, B. (1984). Raisons Practiques. Paris: Kirsh, D. (2010). "Thinking with External RepresenSeuil. tations" Al and Society, 25: 441-454.

Cicourel, A. (1974). Cognitive Sociology. New York: The Free Press.

Clark, A. (2001). Mindware. New York: Oxford University Press.

DeNora, T. (2014). Making Sense of Reality: Culture and Perception in Everyday Life. London: Sage.

Fauconnier. G. \& Turner, M. (2002). The Way We Think. New York: Basic Books.

Fourcade, M. (2012). "The Vile and the Noble", The Sociological Quarterly, 53, 4: 524-545.

Gibbs, R. W. (2006). Embodiment and Cognitive Science. New York: Cambridge University Press.

Kahneman, A. \& Tversky, D. (1973). "Judgment under Uncertainty: Heuristics and Biases", Science, 185, 4157: 1124-1131.

Hutchins, E. (2012). "Concepts in Practice as Sources of Order" Mind, Culture, and Activity, 19: 3, 314-323.

Lahire, B. \& Rosental, C. (2008). La Cognition au prisme des Sciences sociales. Paris: Éditions des archives contemporaines.

Premack, D. (2004). Is Language the Key to Human Intelligence? Science 303, 318.

Searle, J. (2004). Mind. New York: Oxford University Press.

Schütz, A. (1972). Collected Papers vol. I. The Netherlands: Springer.

Wacquant, L. (2000). Body and soul: Notebooks of an apprentice boxer. New York: Oxford University Press. 
